\title{
Effects of post-encoding stress on performance in the DRM false memory paradigm
}

\author{
Enmanuelle Pardilla-Delgado, Sara E. Alger, Tony J. Cunningham, Brian Kinealy, \\ and Jessica D. Payne \\ Department of Psychology, University of Notre Dame, Indiana 46556, USA
}

\begin{abstract}
Numerous studies have investigated how stress impacts veridical memory, but how stress influences false memory formation remains poorly understood. In order to target memory consolidation specifically, a psychosocial stress (TSST) or control manipulation was administered following encoding of 15 neutral, semantically related word lists (DRM false memory task) and memory was tested $24 \mathrm{~h}$ later. Stress decreased recognition of studied words, while increasing false recognition of semantically related lure words. Moreover, while control subjects remembered true and false words equivalently, stressed subjects remembered more false than true words. These results suggest that stress supports gist memory formation in the DRM task, perhaps by hindering detail-specific processing in the hippocampus.
\end{abstract}

[Supplemental material is available for this article.]

Although memory was once believed to be an accurate, reproductive representation of life experience, it is now understood to be a reconstructive process that is susceptible to distortion (Bartlett 1932; Schacter 1995). If even memories formed in the best conditions are prone to errors and illusions, what happens to memories formed under less than ideal circumstances, such as during times of stress? This topic has garnered attention for its impact on the accuracy of eyewitness testimony after witnessing stressful events (Deffenbacher et al. 2004; Schacter and Loftus 2013), but has even broader naturalistic relevance considering that many life events are accompanied by stress (e.g., death, divorce, change in career, etc.). Given the ubiquitous nature of stress in our lives, and the fact that stress alters memory function, it is critical to understand how stress influences not just the formation of true, accurate memories, but of false memories as well.

Research on stress and memory has grown considerably over the past several decades (Het et al. 2005; Diamond et al. 2007; de Quervain et al. 2009; Roozendaal et al. 2009; Wolf 2009; Schwabe et al. 2011), but only a handful of studies have investigated the influence of stress on false memory formation (e.g., Payne et al. 2002; Smeets et al. 2006, 2008; Beato et al. 2013; Zoladz et al. 2014). Most have used the Deese-Roediger-McDermott, or "DRM," false memory paradigm (Deese 1959; Roediger and McDermott 1995), in which participants study lists of semantically related words (e.g., nurse, hospital, medicine) and later falsely remember unstudied "critical words" (e.g., doctor) that represent the theme, or gist, of the list. In spite of using the same memory task, and often the same stress induction procedure to increase levels of the stress hormone cortisol (the Trier Social Stress Test, TSST, Kirschbaum et al. 1993), these studies have returned conflicting results.

In the first test of stress and false memory, Payne et al. (2002) found that stress exposure increased false recognition memory. Conversely, Smeets et al. (2006) found that false memory was unaffected by stress, while true recall memory was impaired. More recently, Beato et al. (2013) found no effect of stress on either true or false memory, while Zoladz et al. (2014) found that stress reduced

\section{Corresponding author: jpayne7@nd.edu}

Article is online at http://www.learnmem.org/cgi/doi/10.1101/Im.039354.115. immediate false memory, while increasing true memory in females, but not males. Due to differences in the timing and mode of memory testing, it is difficult to directly compare the results of these studies. For example, while Payne et al. (2002) used four-item recognition tests after each wordlist, Smeets et al. (2006) used free recall tests after each list followed by a final recognition test, Beato et al. (2013) used a single recognition list after all wordlists, and Zoladz et al. (2014) used free recall and recognition tests after each wordlist. Even more problematic, however, is the fact that these studies administered stress prior to encoding and tested memory in a relatively brief experimental session, which allowed stress hormones to remain elevated throughout all phases of memory formation (encoding, early consolidation, and retrieval). Given that stress tends to facilitate encoding and consolidation, especially for emotionally arousing information (although note that stress can disrupt memory for neutral information; Buchanan and Lovallo 2001; Payne et al. 2006, 2007), but impair retrieval (de Quervain et al. 2009), this design makes it difficult to determine where in the memory formation process stress had its greatest impact.

In order to dissociate the effects of stress on different phases of memory, Smeets et al. (2008) manipulated stress before encoding, after encoding, or before retrieval using five emotionally negative and five neutral DRM lists. Memory was tested $24 \mathrm{~h}$ after encoding, ensuring that subjects in the encoding and consolidation groups were no longer influenced by elevated cortisol. Stress applied prior to encoding yielded no group differences, while stress induced at retrieval decreased true recall of emotional words only. Most relevant to the current study, stress applied after encoding (targeting consolidation) had no effect on false recall of neutral or emotional words, but increased recall of true emotional words.

\footnotetext{
C 2015 Pardilla-Delgado et al. This article is distributed exclusively by Cold Spring Harbor Laboratory Press for the first 12 months after the full-issue publication date (see http://learnmem.cshlp.org/site/misc/terms.xhtml). After 12 months, it is available under a Creative Commons License (AttributionNonCommercial 4.0 International), as described at http://creativecommons. org/licenses/by-nc/4.0/.
} 
While this is the only study to investigate the impact of stress on consolidation, it nonetheless utilized both emotional and neutral DRM lists, cold pressor stress (CPS) as opposed to psychosocial stress, an all-female sample, and a stem-cued recall test uncommon in DRM literature, which makes it difficult to compare to the previously described studies. More important, it may not have been sufficiently powered to demonstrate how stress impacts consolidation of neutral false memories in the DRM task, where more than five neutral word lists are typically used (e.g., Roediger and McDermott 1995). Related to this power issue, the inclusion of both neutral and emotional stimuli might have resulted in an emotional-over-neutral memory benefit during the consolidation delay, which may help explain the null findings for neutral memory in the Smeets study (Hadley and Mackey 2006; Payne et al. 2008).

The present study was thus designed to investigate the effect of psychosocial stress (TSST) on the consolidation of 15 emotionally neutral DRM lists across a 24-h delay, using both free recall and recognition tests to fully probe memory. Based on the idea that contextual processing of detail-based, neutral veridical memories in the hippocampus and associated areas might be disrupted by stress while gist processing of false memories in neocortical regions (e.g., anterior temporal areas) might be spared (Nadel et al. 2002; Payne et al. 2004; Garoff-Eaton et al. 2007; Gallate et al. 2009), we hypothesized that stress administered immediately after encoding would impair true memory while leaving false memory unaffected or even enhanced.

Participants arrived at the laboratory between 3-4 p.m. and signed informed consent. After a 20-min acclimation period, they provided a $5 \mathrm{~mL}$ saliva sample in order to establish a baseline level of cortisol. Six saliva samples in total were collected from each participant across the experimental days to determine salivary cortisol response to the TSST or control task as a measure of hypothalamic-pituitary-adrenal (HPA) axis reactivity to stress (see Supplemental Fig. S1). After participants completed the first sample, they encoded 15 DRM lists (Stadler et al. 1999) and were then randomly assigned to a stress condition using the TSST that involved giving an evaluated speech followed by a math task $(n=33,18$ females) or a closely matched control condition $(n=$ 34; 23 females); see Supplemental Material for additional details about participants and the experimental/control TSST procedures.

Twenty-four hours after the stress (or control) manipulation, participants returned to the laboratory for the testing session, where a free recall test was given, followed immediately by a recognition test. Participants saw a word on a computer screen and had to indicate whether they remembered it from the last session. The recognition test consisted of 92 words divided into three categories: study words (TRUE), unpresented related critical lures (FALSE), and unpresented unrelated words (FOIL). Presented words were chosen from positions 1,8 , and 10 of the lists for a total of 45 presented words (exp. 2; Roediger and McDermott 1995; Fenn et al. 2009). Thirty-two foils were taken from eight unused DRM lists (four from each list). Finally, the 15 unpresented critical lures were included. The 92 words were randomly presented.

To assess the impact of the TSST versus control manipulation on cortisol reactivity, a 2 (Group) $\times 6$ (Time: $T_{0}, T_{1}, T_{2}, T_{3}, T_{4}, T_{5}$ ) mixed ANOVA using the Greenhouse-Geisser correction was performed, with Time of salivary cortisol collection as a repeated factor (see Supplemental Fig. S2A). There were no main effects of Time $(F=1.74, P=0.16)$ or Group $(F=0.96, P=0.33)$, yet the interaction was significant, $\left.F_{(3,199)}=4.78, P=0.003\right)$. Follow-up $t$-tests showed that there was no difference at baseline $\left(T_{0} ; t=\right.$ $1.42, P=0.16), 60$ min post-manipulation $\left(T_{3} ; t=0.76, P=\right.$ $0.45)$, or on the second day $\left(T_{4}, T_{5} ; t=0.68, P=0.49, t=0.31\right.$, $P=0.76$, respectively). As expected, the stress group had significantly higher cortisol responses immediately after and $20 \mathrm{~min}$ af- ter the manipulation $\left(T_{1}, T_{2} ; t=2.35, P=0.02, t=2.19, P=0.03\right.$, respectively). See Supplemental Figure S2B for these data broken down to only high cortisol responders; creating this variable allowed us to examine memory performance in both the stress group as a whole, and in only those subjects who mounted a cortisol response to the TSST (see Supplemental Materials).

Because the memory performance patterns emerged most clearly in the recognition data, we address these first. True recognition was calculated as hit rate ("old" responses to study words divided by the total number [45] of study words) minus false alarm rate to foils ("old" responses to unrelated foils divided by the total number [32] of unrelated foils); false recognition was calculated as false alarm rate to critical lures ("old" responses to related lures [e.g., doctor] divided by the total number [15] of related lures) minus false alarm rate to foils (e.g., Diekelmann et al. 2008). A 2 (Group: stress versus control) $\times 2$ (Word Type: True versus False) mixed ANOVA, with Word Type as repeated factor, revealed no main effect of Group, $F_{(1,65)}<0.01, P=0.97$, but a significant main effect of Word Type $\left(F_{(1,65)}=6.24, P=0.02\right)$ indicating that true recognition $(M=0.29)$ was lower than false recognition of the critical lures $(M=0.36 ; P=0.02)$. This finding indicates a robust false recognition effect. Importantly, the Group $\times$ Word Type interaction was significant $\left(F_{(1,65)}=3.89, P=0.05\right)$, reflecting a general pattern where stress decreased recognition for studied words, but increased recognition for critical lures (Fig. 1A).
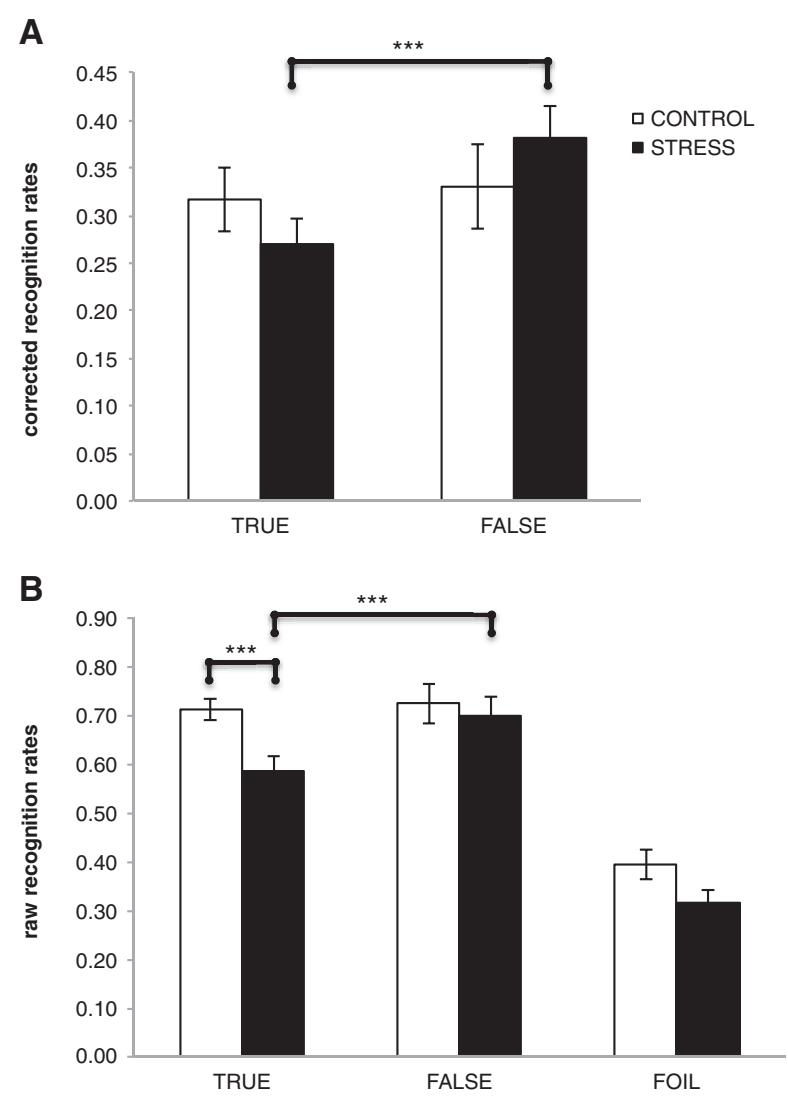

Figure 1. (A) Corrected recognition rates for TRUE memory (hit rateFA to unrelated foils) and FALSE memory (FA to critical lures-FA to unrelated foils). The stressed participants recognized more FALSE words than TRUE words. (B) Raw recognition rates for studied words (TRUE), critical lures (FALSE), and unpresented words (FOILS). The stress group showed decreased true recognition compared with the control group. Within the stress group, participants remembered more false words than true words. $(* * *) P<0.001$. 
Although group differences were not detected for corrected true $\left[t_{(65)}: 1.01, P=0.28\right]$, or false $\left[t_{(65)}: 0.94, P=0.35\right]$ recognition, these differences did emerge in the raw recognition scores (Fig. 1B). Memory for true words was significantly impaired in the stress group $(M=0.58)$, relative to controls $\left(M=0.71 ; t_{(65)}=3.39, P=\right.$ 0.001; Fig. 1B, first two bars). Importantly, stressed participants significantly recognized proportionately more false than true words, $t_{(32)}=4.23, P<0.001$, while control participants recognized true and false words at similar rates, $t_{(33)}=0.31, P=0.76$ ).

Cortisol-responder subgroup analyses suggest that the stress effects on false memory are dependent on mounting a cortisol response (Fig. 2A). For corrected recognition, a 2 (Group: control versus high responders) $\times 2$ (Word Type)-mixed ANOVA again revealed a significant interaction, $F_{(1,48)}=4.15, P=0.047$, which supports our initial finding. Although differences did not emerge between the groups $\left(t_{(48)}=0.75, P=0.46\right.$ for true, $t_{(48)}=1.37, P=$ 0.17 for false memory), the significant interaction demonstrates that while controls recognized true and false words similarly $\left(t_{(33)}=0.31, P=0.76\right)$ high responders recognized more false than true words $\left(t_{(15)}=4.81, P=0.001\right)$. This suggests that stress, and particularly a stress-related cortisol increase, leads to an increased reliance on gist-based processing (see Nadel et al. 2002; Pedraza et al. 2015). Figure 2B shows that a strong cortisol response to stress also affects memory bias, as confirmed by a significant Group $\times$ Word Type interaction, $F_{(1,48)}=4.51, P=0.04$; the stress group, compared with controls, tended to be more conserva-
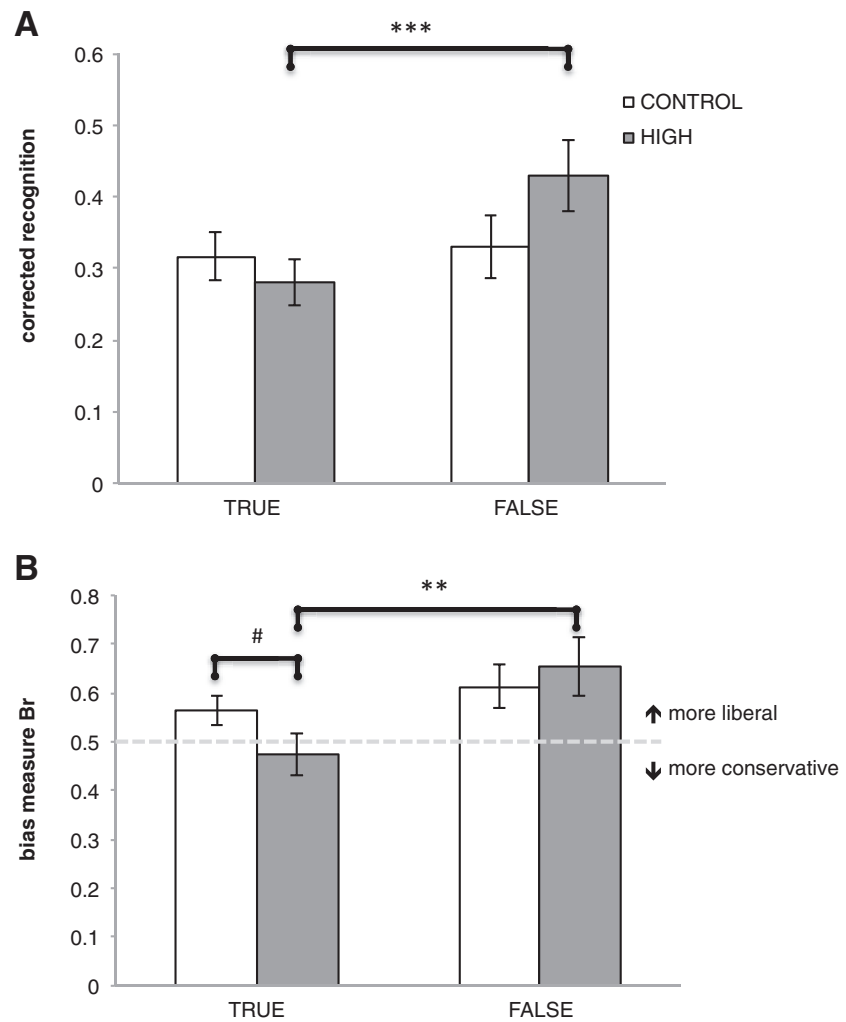

Figure 2. The stress group was divided into two subgroups by a median split of the cortisol change score (AUCi), allowing us to compare controls to $\mathrm{HIGH}$ cortisol responders. While control subjects had equivalent memory for true and false words $(A$, white) and were equally biased to respond to true and false words ( $B$, white), a shift toward false memory is evident in the high cortisol responders (gray). Dashed line indicates the "no bias" point $(0.5)$, whereas $<0.5$ indicates a conservative bias and $>0.5$ indicates a liberal bias. (\#) $P=0.09\left(^{* *}\right) P<0.005\left(^{* * *}\right) P<$ 0.001 . tive when recognizing true words $\left(t_{(48)}=1.69, P=0.09\right)$ while also tending to be more liberal when recognizing false words, albeit only numerically $\left(t_{(48)}=0.51, P=0.60\right)$. High responders were more liberal in response to false words, compared with true words $(t=3.28, P=0.005)$, whereas controls were equally biased $(t=1.56, P=0.13)$. These results provide additional support for the idea that cortisol exposure may increase reliance on gist-based processing during consolidation (Brainerd and Reyna 1998; Nadel et al. 2002; Payne et al. 2002; Pedraza et al. 2015).

While no significant differences emerged between the groups in recall memory, it is worth noting that the pattern numerically followed that reported for recognition memory above, with planned comparisons again revealing that true recall of studied words was numerically decreased in the stress group $(M=14.9$, $\mathrm{SD}=7.8)$ compared with the control group $(M=17.5, \mathrm{SD}=$ $9.9), t_{(65)}=1.69, P=0.25$ (see Supplemental Table S2). False recall $(t=0.07, P=0.94)$ and intrusions $(t=0.18, P=0.86)$ were not significantly different between groups.

Importantly, we also found that larger stressor-related increases in cortisol (AUCi in the stress group) were associated with greater susceptibility to false memory; false recognition showed a strong trend $(r=0.33, P=0.059)$, while bias to critical lures ( $r=0.42, P=0.02$ ) was positively correlated to AUCi (Fig. 3 ).

Previous studies (e.g., Kim and Cabeza 2007; Payne et al. 2009) have found a positive correlation between gist-based false memory and true memory in the DRM paradigm, suggesting that semantic/gist processing contributes to the formation of both false and veridical memory, at least in tasks like the DRM that present semantically related stimuli. Similar correlations were found in the current study (Supplemental Fig. S3), but, interestingly, only in the stress group $(r=0.72, P<0.001$ for recognition, $r=0.50, P=0.003$ for recall); there was no relationship between false and true memory in the control group $(r=0.21$, $P<0.25$ for recognition, $r=0.27, P=0.12$ for recall), further suggesting that stress exposure promotes a greater reliance on gistbased processing.

The current study assessed the role of psychosocial stress on neutral memory consolidation in the DRM paradigm. Our results demonstrate that post-encoding stress impaired subsequent memory for true (studied) words. Moreover, while nonstressed control participants remembered (and were equally biased to) true and false memories equivalently, stressed participants remembered more (and had a liberal bias toward) false memories. Both of these results have important implications for real-world memory and eyewitness memory in the courtroom as we discuss below.

To date, only two studies have investigated the impact of stress on true and false memory consolidation-smeets et al. (2008) and the current study. While Smeets et al. (2008) found that stress enhanced true memory for emotional words, we found that stress impaired true memory for neutral words. The different findings may in part arise from methodological differences. First, we used psychosocial stress (TSST) instead of CPS as it is an ecologically valid stressor that often elicits stronger HPA and sympathetic nervous system responses than CPS (McRae et al. 2006; Goff et al. 2013), although it should be noted that cortisol levels in the present study were similar to those achieved by Smeets et al. (2008). Second, we used 15 neutral word lists, increasing power for a more accurate DRM "neutral" memory result. The mixture of emotional and neutral words used in the Smeets et al. (2008) study may have resulted in emotional and neutral material competing for memory resources during consolidation, thus resulting in a null effect of stress on neutral memory (e.g., Hadley and MacKay 2006; Payne et al. 2008). Third, we used both free recall and recognition tests (e.g., Roediger and McDermott 1995) instead of the less common stem-cued recall test. Finally, Smeets et al. sampled exclusively female participants (for their 

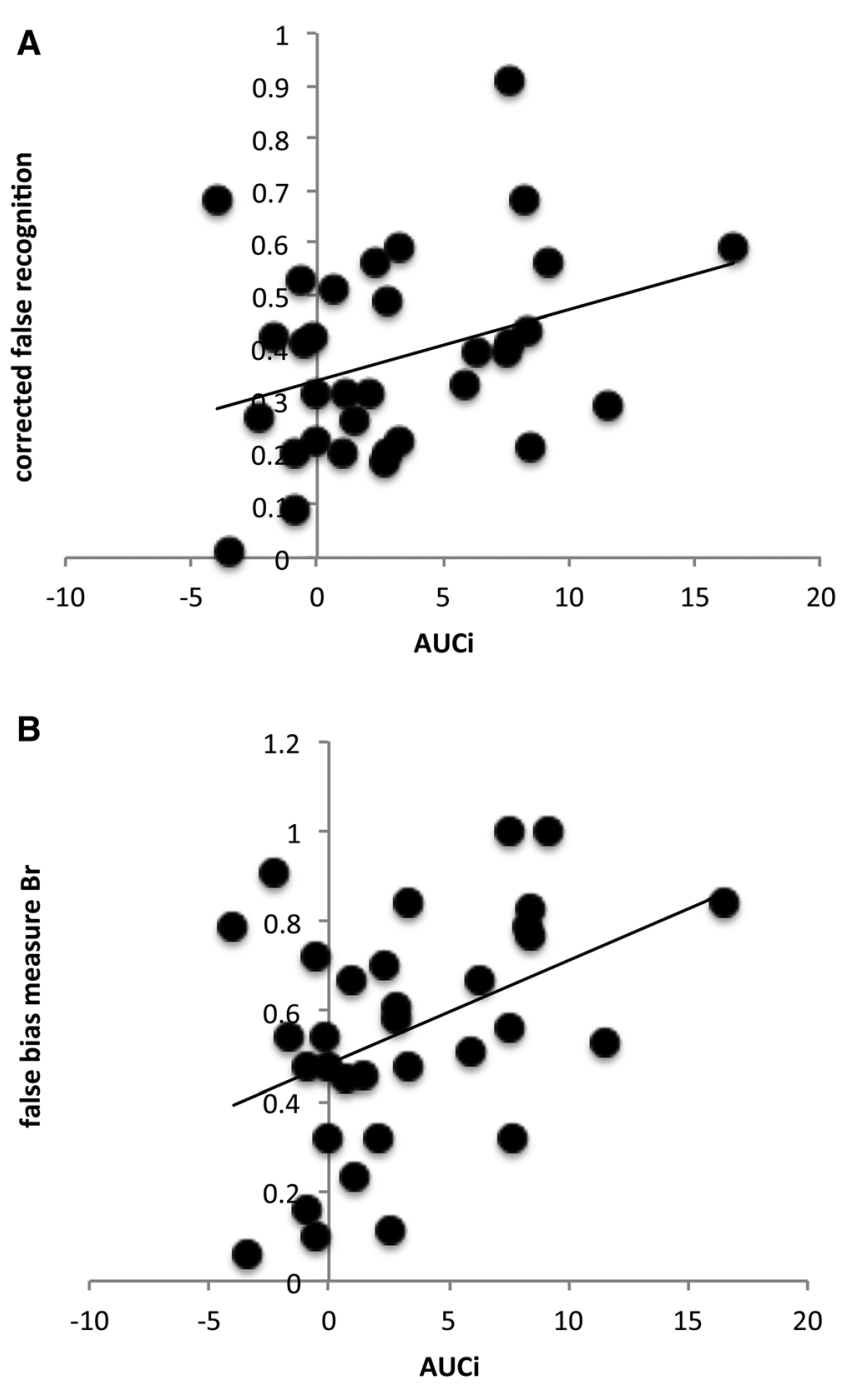

Figure 3. For the stress group, stressor-related increases in cortisol (AUCi) were positively correlated with $(A)$ corrected false recognition $(r=0.33, P=0.059)$ and $(B)$ bias to false words $(r=0.42, P=0.02)$.

consolidation group), while we tested both females and males, which increases the generalizability of the findings.

Although our findings may at first seem at odds with the literature demonstrating enhanced memory consolidation under stress (de Quervain et al. 2009; Wolf 2009), it is important to note that stress often confers a benefit to memory for emotional material (as in Smeets et al. 2008), while sometimes impairing memory for neutral material, as we see here (Jelicic et al. 2004; Payne et al. 2006, 2007; Smeets et al. 2008; de Quervain et al. 2009; but see Andreano and Cahill 2006; Smeets et al. 2007). Evidence suggests that brain regions involved in emotional (e.g., amygdala) and neutral memory consolidation (e.g., hippocampus) are differentially impacted by elevated stress and cortisol (Payne et al. 2004, 2006, 2007). For example, while high levels of stress and cortisol often disrupt hippocampal function, they potentiate activity in the amygdala (e.g., Vyas et al. 2002; van Stegeren et al. 2007a,b; Pruessner et al. 2008; Ghosh et al. 2013). Our results are consistent with this idea in that, using only neutral lists, impairment of hippocampal processing by stress may have disrupted veridical memory for studied words (see also Smeets et al. 2006), while the emotional words used by Smeets et al.
(2008) may have benefited from stress, because they rely on amygdala activation.

One explanation of our results involves a gist-based model of memory formation, which argues that all learned specific events (studied words) share more common features with the gist (critical lures) than with each other. This results in an increased reliance on gist processing, which produces false memories for critical words that were never presented (Brainerd et al. 2002; Brainerd and Reyna 2005). It may be that gist representations are more stable at the time of consolidation after receiving repeated activation with each studied word, resulting in stronger associative connections and increased resistance to stress. Specific-event representations (studied words), on the other hand, having received weaker activation, may be more susceptible to post-encoding stress. Similar to this idea, Payne et al. (2002) suggested that context-based processing of detailed, emotionally neutral memories can be impaired by stress through disruption of hippocampal functioning. Neocortical (anterior temporal) regions might compensate, allowing gist-based processing to "take over" (also see Nadel et al. 2002; Payne et al. 2004). Oyarzún and Packard (2012) also suggest that stress, through sensory hypersensitivity caused by the noradrenergic system (Aston-Jones and Cohen 2005), may generate generalized responses to stimuli, which results in a bias shift toward gist-based processing. The current findings are also consistent with recent rodent studies showing that intense stress exposure leads to a faster generalization (i.e., gist formation) in memory than weak stress exposure (Pedraza et al. 2015). Interestingly, this gist formation acceleration was dependent on glucocorticoid synthesis and noradrenergic release. In the current study, a similar enhancement of gist processing may have occurred due to stress exposure, resulting in impaired true memory and higher recognition rates and a more liberal bias for false memories than true memories in stressed participants.

The finding that accurate memory suffers under stress has clear relevance for eyewitness testimony in the courtroom (Schacter and Loftus 2013), where the veracity of memories, even those formed during times of stress, is often assumed. Our findings not only make an important contribution to a growing literature on stress and memory in humans, but the fact that our stressed participants remembered more false than true information further underscores the importance of using caution when evaluating the accuracy of memories formed under stress in the real world (see Deffenbacher et al. 2004).

More research is needed to determine the full range of stress effects on the different phases of memory formation, especially where false memories are concerned. This is one of few studies of stress and false memory, and one of only two examining the impact of stress on the consolidation phase of true and false memory formation. Additional work will also be necessary to determine whether stress effects on DRM performance generalize to other forms of false memory. Although we already know that memory does not operate like a foolproof video recording that can simply be replayed to accurately remember information, such efforts will be necessary if we are to arrive at a more comprehensive understanding of how stress influences the formation of both true and false memories.

\section{Acknowledgments}

We thank everyone from the Sleep, Stress, and Memory (SAM) Laboratory for their assistance with data collection.

\section{References}

Andreano JM, Cahill L. 2006. Glucocorticoid release and memory consolidation in men and women. Psychol Sci 17: 466-470. 
Aston-Jones G, Cohen JD. 2005. An integrative theory of locus coeruleus-norepinephrine function: adaptive gain and optimal performance. Annu Rev Neurosci 28: 403-450.

Bartlett FC. 1932. Remembering: an experimental and social study. Cambridge University, Cambridge.

Beato MS, Cadavid S, Pulido RF, Pinho MS. 2013. No effect of stress on false recognition. Psicothema 25: 25-30.

Brainerd CJ, Reyna VF. 1998. Fuzzy-trace theory and children's false memories. J Exp Child Psychol 71(2): 81-129.

Brainerd CJ, Reyna VF. 2005. The science of false memory. Oxford University Press, New York.

Brainerd CJ, Reyna VF, Forrest TJ. 2002. Are young children susceptible to the false-memory illusion? Child Dev 75: 1363-1377.

Buchanan TW, Lovallo WR. 2001. Enhanced memory for emotional material following stress-level cortisol treatment in humans. Psychoneuroendocrinology 26: 307-317.

Deese J. 1959. On the prediction of occurrence of particular verbal intrusions in immediate recall. I Exp Psychol 58: 17.

de Quervain DJF, Aerni A, Schelling G, Roozendaal B. 2009. Glucocorticoids and the regulation of memory in health and disease. Front Neuroendocrinol 30: 358-370.

Deffenbacher KA, Bornstein BH, Penrod SD, McGorty EK. 2004. A meta-analytic review of the effects of high stress on eyewitness memory. Law Hum Behav 28: 687-706.

Diamond DM, Campbell AM, Park CR, Halonen J, Zoladz PR. 2007. The temporal dynamics model of emotional memory processing: a synthesis on the neurobiological basis of stress-induced amnesia, flashbulb and traumatic memories, and the Yerkes-Dodson law. Neural Plast 2007: 1-33.

Diekelmann S, Landolt HP, Lahl O, Born J, Wagner U. 2008. Sleep loss produces false memories. PLoS One 3: e3512.

Fenn KM, Gallo DA, Margoliash D, Roediger HL 3rd, Nusbaum HC. 2009. Reduced false memory after sleep. Learn Mem 16: 509-513.

Gallate J, Chi R, Ellwood S, Snyder A. 2009. Reducing false memories by magnetic pulse stimulation. Neurosci Lett 449: 151-154.

Garoff-Eaton RJ, Kensinger EA, Schacter DL. 2007. The neural correlates of conceptual and perceptual false recognition. Learn Mem 14: 684-692.

Ghosh S, Laxmi TR, Chattarji S. 2013. Functional connectivity from the amygdala to the hippocampus grows stronger after stress. J Neurosci 33: $7234-7244$

Goff L, Ali N, Pruessner J. 2013. Stress reactivity during evaluation by the opposite sex: comparison of responses induced by different psychosocial stress tests. McGill Sci Undergrad Res J 8: 11-17.

Hadley CB, MacKay DG. 2006. Does emotion help or hinder immediate memory? Arousal versus priority-binding mechanisms. J Exp Psychol Learn Mem Cogn 32: 79-88.

Het S, Ramlow G, Wolf OT. 2005. A meta-analytic review of the effects of acute cortisol administration on human memory. Psychoneuroendocrinology 30: 771-784.

Jelicic M, Geraerts E, Merckelbach H, Guerrieri R. 2004. Acute stress enhances memory for emotional words, but impairs memory for neutral words. Int J Neurosci 114: 1343-1351.

Kim H, Cabeza R. 2007. Differential contributions of prefrontal, medial temporal, and sensory-perceptual regions to true and false memory formation. Cereb Cortex 17: 2143-2150.

Kirschbaum C, Pirke KM, Hellhammer DH. 1993. The 'Trier Social Stress Test' - a tool for investigating psychobiological stress responses in a laboratory setting. Neuropsychobiology 28: 76-81.

McRae AL, Saladin ME, Brady KT, Upadhyaya H, Back SE, Timmerman MA. 2006. Stress reactivity: biological and subjective responses to the cold pressor and Trier Social stressors. Hum Psychopharmacol 21: 377-385.

Nadel L, Payne JD, Jacobs WJ. 2002. The relationship between episodic memory and context: clues from memory errors made while under stress. Physiol Res 9: 74-89.

Oyarzún J, Packard P. 2012. Stress-induced gist-based memory processing: a possible explanation for overgeneralization of fear in posttraumatic stress disorder. J Neurosci 32: 9771-9772.

Payne JD, Nadel L, Allen JJ, Thomas KG, Jacobs WJ. 2002. The effects of experimentally induced stress on false recognition. Memory 10: $1-6$.
Payne JD, Nadel L, Britton WB, Jacobs WJ. 2004. The biopsychology of trauma and memory. In Memory and emotion. Series in affective science (ed. Reisberg D, Hertel P), pp. 76-128. Oxford University Press, New York.

Payne JD, Jackson ED, Ryan L, Hoscheidt S, Jacobs JW, Nadel L. 2006. The impact of stress on neutral and emotional aspects of episodic memory. Memory 14: $1-16$

Payne JD, Jackson ED, Hoscheidt S, Ryan L, Jacobs WJ, Nadel L. 2007. Stress administered prior to encoding impairs neutral but enhances emotional long-term episodic memories. Learn Mem 14: 861-868.

Payne JD, Stickgold R, Swanberg K, Kensinger EA. 2008. Sleep preferentially enhances memory for emotional components of scenes. Psychol Sci 19: $781-788$.

Payne JD, Schacter DL, Propper RE, Huang LW, Wamsley EJ, Tucker MA, Walker MP, Stickgold R. 2009. The role of sleep in false memory formation. Neurobiol Learn Mem 92: 327-334.

Pedraza LK, Sierra RO, Boos FZ, Haubrich J, Quillfeldt JA, de Oliveira Alvares L. 2015. The dynamic nature of systems consolidation: stress during learning as a switch guiding the rate of the hippocampal dependency and memory quality. Hippocampus doi: 10.1002/ hipo. 22527.

Pruessner JC, Dedovic K, Khalili-Mahan N, Engert V, Pruessner M, Buss C, Renwick R, Dagher A, Meaney MJ, Lupien S. 2008. Deactivation of the limbic system during acute psychosocial stress: evidence from positron emission tomography and functional magnetic resonance imaging studies. Biol Psychiatry 63: 234-240.

Roediger HL, McDermott KB. 1995. Creating false memories: remembering words not presented in lists. J Exp Psychol Learn Mem Cogn 21: 803-814.

Roozendaal B, McEwen BS, Chattarji S. 2009. Stress, memory and the amygdala. Nat Rev Neurosci 10: 423-433.

Schacter DL. 1995. Memory distortions: how minds, brains, and societies reconstruct the past. Harvard University Press, Cambridge, MA.

Schacter DL, Loftus EF. 2013. Memory and law: what can cognitive neuroscience contribute? Nat Neurosci 16: 119-123.

Schwabe L, Joëls M, Roozendaal B, Wolf OT, Oitzl MS. 2011. Stress effects on memory: an update and integration. Neurosci Biobehav Rev 36: 1740-1749.

Smeets T, Jelicic M, Merckelbach H. 2006. Stress-induced cortisol responses sex differences and false recollections in a DRM paradigm. Biol Psychol 72: $164-172$.

Smeets T, Giesbrecht T, Jelicic M, Merckelbach HLGJ. 2007. Context-dependent enhancement of declarative memory performance following acute psychosocial stress. Biol Psychol 76: 116-123.

Smeets T, Otgaar H, Candel I, Wolf OT. 2008. True or false? Memory is differentially affected by stress-induced cortisol elevations and sympathetic activity at consolidation and retrieval. Psychoneuroendocrinology 33: 1378-1386.

Stadler MA, Roediger HL III, McDermott KB. 1999. Norms for word lists that create false memories. Mem Cognit 27: 494-500.

van Stegeren AH, Wolf OT, Everaerd W, Rombouts SA. 2007a. Interaction of endogenous cortisol and noradrenaline in the human amygdala. Prog Brain Res 167: 263-268.

van Stegeren AH, Wolf OT, Everaerd W, Scheltens P, Barkhof F, Rombouts SA. 2007b. Endogenous cortisol level interacts with noradrenergic activation in the human amygdala. Neurobiol Learn Mem 87: $57-66$.

Vyas A, Mitra R, Shankaranarayana Rao BS, Chattarji S. 2002. Chronic stress induces contrasting patterns of dendritic remodeling in hippocampal and amygdaloid neurons. J Neurosci 22: 6810-6818.

Wolf OT. 2009. Stress and memory in humans: twelve years of progress? Brain Res 1293: 142-154.

Zoladz PR, Peters DM, Kalchik AE, Hoffman MM, Aufdenkampe RL, Woelke SA, Wolters NE, Talbot JN. 2014. Brief, pre-learning stress reduces false memory production and enhances true memory selectively in females. Physiol Behav 128: 270-276.

Received June 16, 2015; accepted in revised form October 28, 2015. 


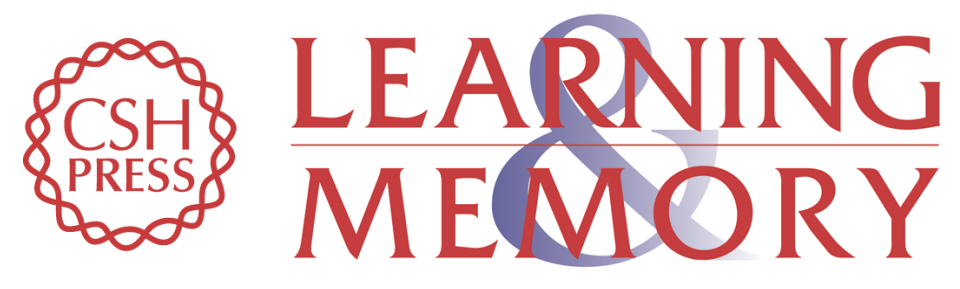

\title{
Effects of post-encoding stress on performance in the DRM false memory paradigm
}

\author{
Enmanuelle Pardilla-Delgado, Sara E. Alger, Tony J. Cunningham, et al.
}

Learn. Mem. 2016, 23:

Access the most recent version at doi:10.1101/Im.039354.115

\section{Supplemental http://learnmem.cshlp.org/content/suppl/2015/12/08/23.1.46.DC1 Material}

References This article cites 44 articles, 6 of which can be accessed free at: http://learnmem.cshlp.org/content/23/1/46.full.html\#ref-list-1

Creative This article is distributed exclusively by Cold Spring Harbor Laboratory Press for the Commons first 12 months after the full-issue publication date (see

License http://learnmem.cshlp.org/site/misc/terms.xhtml). After 12 months, it is available under a Creative Commons License (Attribution-NonCommercial 4.0 International), as described at http://creativecommons.org/licenses/by-nc/4.0/.

Email Alerting Receive free email alerts when new articles cite this article - sign up in the box at the Service top right corner of the article or click here. 